\title{
The Over-Patologization and Over-Medicalization of Children: a Current Problem
}

\author{
Alejandra Taborda \\ Agustina Labin
}

\begin{abstract}
Currently vertiginous modifications carve tense coexistence between old and new paradigms. Embedded in the hasty, unprecedented subjective expressions appear on the scene, with such celerity that the existing linguistic categories are not enough to embrace them, to name them, to describe them as such - at best - are partially thought out. The empty spaces left by language promote the languages of segregation. The over-patologization and over-medicalization of children due to school difficulties and / or attentional difficulties are privileged ways of expressing exclusion movements. The Argentina Mental Health law ( ${ }^{\circ} 26657$ ) open spaces for reworking the parameters and conceptual matrices involved in psychodiagnostics, in order to promote readings of transdisciplinary interrelations centered on human rights. In order to understand the theoretical and clinical complexity of the psychodiagnosis of children, the ongoing research project, endorsed of the San Luis University (Argentina) included: 1. Epidemiological studies of the consultation. 2. Development of diagnostic and therapeutic resources. 3. Etiological review of the symptom. 4. Analysis of therapeutic effectiveness. 5. Comparison of two psychoanalytic psychotherapeutic modalities (parallel group of parents and children versus individual treatment of the child. The clinical and empirical studies allow us to propose, within the framework of an extended diagnostic device, a new diagnostic indicator: the evolution of attentional difficulties - after six months to one year of psychotherapy - before resorting to pharmacological treatments. It is emphasized that diagnosis in a person's life is never neutral, therapeutic or iatrogenic.
\end{abstract}

Keywords: The Over-Patologization and Over-Medicalization of Children: a Current Problem 